International Journal of Innovative Studies in Aquatic Biology and Fisheries Volume 6, Issue 3, 2020, PP 34-42

ISSN No.: 2454-7670

DOI: https:// doi.org/10.20431/2454-7670.0603005

www.arcjournals.org

\title{
Shrimp Culture
}

\author{
Anupma kumari * \\ Research scholar Magadh university, Bodh Gaya, India
}

*Corresponding Author: Anupma kumari, Research scholar Magadh university, Bodh Gaya, India

\begin{abstract}
Sunderban woodlands are a stretch of immune woods lying at part of southern tip of Indian state of west Bengal and stretches to Bangladesh Mangroves are among the naturally most gainful organic frameworks on earth and have generally $75 \%$ of the world's tropical coastlines. Mangroves reinforce more than 80 kinds of verdure and 1300 sorts of fauna and go about as nursery common environmental factors for fish and shellfish of business regard. Moreover, mangrove swamps are incredible in sediment getting, supplement reusing and confirmation of shorelines from breaking down similarly as give incalculable socio-monetarily crucial product, for instance, food, fuel wood, amble, nectar, wax and tannin.it is also a bit of world greatest delta formed by the three conduits Ganga, Brahmaputra and meghna. Consistent redirection of land from mangroves to other land uses, generally agribusiness, shrimp lakes, home and profound deforestation from eighteenth century onwards realized dynamic drop of forest area domain. The Indian bit of Sunderbans is of $9630 \mathrm{sq}$. $\mathrm{km}$ in locale containing 54 involved and 52 forested islands There are 4 indisputable zones for the board purposes in the Indian Sunderbans, specifically (1) Core zone (1700 sq. km) of the inside and out directed Tiger Reserve, (2) Manipulation zone (2400 sq. km) of mangroves incorporating the inside regions, (3) Restoration zone (200 sq. $\mathrm{km})$ of undermined and upset mangroves and (4) Balance zone of non-forest area land businesses. The last three zones are transitional in nature and need remarkable thought if there ought to emerge an event of afforestation works out, soil-water-streaming resource the board, cultivation, aquaculture and human resource headway to diminish the anthropogenic obstacle and dynamic destruction of mangroves in the inside zones. The whole of Sunderbans is depicted by a variety of calculating and aquacultural activities including waterfront fisheries, pungent water aquaculture, estuarine and riverine fisheries, riverside prawn seed grouping, shrimp developing and a couple of freshwater aquaculture varieties. Yet sea shore front and estuarine calculating and riverside prawn seed arrangement interface most of the workforce of the Sunderbans containing men, women and children, the shrimp farms and cruel water paddy cum prawn culture structures are also getting one of the critical territories of second cash pay for owners of tremendous landholdings. Shrimp culture is an age-old practice taking place in brackish-, salineand freshwaters of the coastal areas of Khulna, Satkhira, Bagerhat and Cox's Bazardistricts. Historically, people trapped tidal water in low-lying intertidal lands byconstructing small dykes to trap water, and harvested naturally occurring shrimp and finfish after three to four months. There was no stocking of fry under this system and only wild seeds of shrimp and fish carried in by tidal waters were allowed to grow; and there was no form of any distinct management. Since then production has undergone a major change
\end{abstract}

During the 1970's, after independence, interest in shrimp production grew withrising prices and demand in international markets. Shrimp farms were established in peripheral lands near the mouths of coastal rivers where inundation of saline water was possible. The success of these early farmers encouraged others to come forward and shrimp ghers (local name for a shrimp farm) were established on land inside saline water protection embankments, called Polders, which had been constructed by the Water Development Board in the late seventies. In Bangladesh shrimp production systems were often dispersed and extensive and relatively few shrimps were harvested at any one place and or at one time. Product had to be transported to local markets where it could be aggregated to a scale useful to traders and processors; but where quality control and product tracking was virtually impossible to manage (IIED 2003). The main cultivated species were, and remain, the black tiger shrimp (locally called bagda) Penaeus monodon. Other farmed shrimp species included brown/speckled shrimp (locally called harina chingri) Metapenaeus monoceros, Indian white prawn (locally called chaka chingri) Fenneropenaeus indicus, green tiger prawn P. semisulcatus and banana prawn $F$. merguiensis and giant river prawns (locally called golda) Macrobrachium rosenbergii. From the late seventies and early eighties, the shrimp culture system expanded steadily. In addition to trapping of natural shrimp seeds, farmers began selective stocking of shrimp post-larvae (PL) caught from the wild. This created a new work opportunity for poorer coastal people who began to collect PL from coastal waters. From the mid-eighties, the Government launched infrastructure development programs together with improved technology dissemination and fiscal incentives for producers and processors. International development partners such as World Bank, Asian Development Bank, Food and Agriculture Organization of the United nation. 


\section{INTRODUCTION}

Brackishwater developing in India has been a standard practice for a serious long time and constrained generally to the bheries (engineered impoundments in coastline wetlands) in Sundarbans, West Bengal, India. Consistent brackishwater aquaculture started in India with tiger shrimp (Penaeus monodon) developing began during mid 1990s. With the introduction of Pacific white shrimp (Penaeus vannamei) during 2009, Indian aquaculture industry has grown rapidly. In addition, certain marine/brackishwater fish, for instance, seabass, mullets, milkfish and pearlspot have shown a lot of assurance. Productive preparing of indigenous Indian white shrimp (Penaeus indicus) and exploratory developing using hatching office made seed by ICAR-Central Institute of Brackishwater Aquaculture (CIBA) demonstrated enabling outcomes. Other than family use, fishery things conveyed from the state were 1.05 million tons of critical worth Indian rupee (INR) 33,4420 million during 2015-16. Indian Sundarbans arranged in the south-east completion of West Bengal offers agreeable condition for advancement of collection of fishes and shrimps. Hardened shrimp and live crab are the key admission things from brackishwater aquaculture in Sundarbans. As the monetary favorable position is progressively conspicuous, there istendency of Sundarbans occupants to move from calculating to aquaculture for better occupation. About $25 \%$ of 2.1 lakh ha potential brackish water areas in West Bengal are under use and the state has been the Indian head in tiger shrimp creation while farmers grasped white leg shrimp developing late appeared differently in relation to other Indian ocean states after productive show by ICAR-CIBA at its assessment network at Kakdwip. There is colossal expansion for reasonable improvement of brackishwater aquaculture in Sundarbans to fulfill the work need utilizing the unused and underused areas and getting impelled developing practices. Troubles looked by Sundarbans aquafarmers ought to be taken care of by appropriate organization instruments like social arrangement of water producers, development assessment and refinement, participatory orchestrating, and cutoff working of key accomplices.

Catchphrases Sundarbans •Brackishwater aquaculture •Technology improvement • Biosecurity measures $\bullet$ Species upgrade $\bullet$ Sustainable headway $\bullet$ Livelihood $\bullet$ Opportunities $\bullet$ Challenges

Reaping is done typically during full moon and 2 days prior and 3 days after the new moon period,with the assistance of traps made of bamboo and cast net.the raising territories profundity is running between 1-3 ft the water trade is done between lunar phases.the regular development of filamentous green growth and other smaller scale/macrophytes in these low lying shallow zones, gives superb condition to characteristic development of shrimps .conventional cultivating doesn't require supplement food .however these days rancher gives supplement food.

\section{METHODS}

We conduct a group discussion in the villages of Satkhira, we conduct interviews. In the center gathering conversations focus group discussions (FGD) PL reapers noticed that "We are concerned with biodiversity misfortune in beach front streams due to PL assortment movement and as needs be we return the non-target get back to the water during assortment". The truth, be that as it may, seen by the creators, was that PL gatherers supposedly threw non-target gets on to the land, where they bite the dust in practically no time, and are not back in to the water as expressed. This included many eggs, brings forth and fry of an assortment of seaside fish, shrimps, crabs and mollusks. Indeed, even where nontarget gets are returned by a couple of the PL authorities (despite the fact that this appeared to be low in number), different factors additionally influence non-target species endurance. $30-45$ minutes is required for pulling, which is depleting for species and deadly for a significant number of the living beings, especially for those caught at the start of the take. When gotten some information about the current biodiversity status of the waterway they get the PL from, the FGD members expressed that biodiversity is in a desperate circumstance what's more, a considerable lot of the once bounteously accessible and significant fishes, shrimps and crabs have now become uncommon or even locally terminated. The PL authorities, notwithstanding, said that PL assortment isn't just to fault, refering to the expanding number of fishers, ruinous gears (fine fit nets) and different factors likewise being answerable for biodiversity misfortune in the stream. Albeit a considerable lot of the PL gatherers knew about the hurtful effect of PL assortment, most couldn't locate an elective method for business, and along these lines several beach front poor, including men, ladies and kids, keep on being included in PL assortment. At present it was additionally seen that gher proprietors will in general incline toward wild PL to incubation facility delivered ones, as they accept the wild PL are more grounded than 
hatchery produced PL, endure longer and develop better. This popularity for wild-got PL by shrimp ranchers additionally expands the enticement in needy individuals to keep getting PL from nature.

\subsection{Customary Rice-Shrimp Culture Frameworks}

Consolidated culture of rice with shrimp presents specific difficulties that have clearly been defeated through neighborhood advancement in various areas. Reconciliation of rice with freshwater prawn cultivating in Bangladesh has been portrayed widely and the advantages of conventional gher frameworks are notable and assessed (Ahmed and Garnett 2010; Ahmed et al. 2008, 2010a). Frameworks for the reconciliation of rice and marine shrimp culture have been depicted less significantly, for instance, Wahab et al. (2003) and Azad et al. (2009) however these records highlight various significant strategies and advancements that make such frameworks fascinating to assess from the viewpoint of versatility and ecocultural improvement. Considering the versatility of exercises, it is imperative to put improvements inside a verifiable setting, offering knowledge to the progression of exercises, development of practices because of patterns and stuns and intergenerational courses of action and moves. Sundarbans mangrove backwoods gave critical natural surroundings to shrimp. The channels and low-lying discouragement of the Sundarbans, prior utilized by the helpless fishers have been transformed into shrimp ranches (Islam and Wahab 2005). Declining creation in nations where shrimp cultivating was first settled, inferable from water and residue quality issues and shrimp ailment flare-ups, adding to rising shrimp costs all inclusive, provoked business, trade situated shrimp culture advancement during the 1980s in Bangladesh (Azad et al. 2009). Also, Milstein et al. (2005; p. 501) noticed that a 'flourishing business sector economy including the beach front aquaculture of marine shrimp (Penaeus monodon) in Bangladesh has steadily evolved during the last half-century, developing from normal stocking in post-harvest rice fields overwhelmed with approaching brackishwater from the Bay of Bengal'. Be that as it may, fast advancement of shrimp cultivating had noteworthy negative ecological effects on the Sundarbans mangrove timberlands. Responsibility for ranches in the Sundarbans is constrained by better-off and influential individuals (Deb 1998). As per Hoq (2008) in the course of the most recent two decades' shrimp culture in the Sundarbans has changed from conventional to broad cultivating and there is an expanding inclination toward improvedextensive cultivating. Shrimp cultivating in a great part of the Sundarbans is closely resembling natural cultivating, and there is a tremendous potential for guaranteed natural shrimp culture.

\subsection{Improvement in Traditional Farming}

Polyculture is possibly more conservative than monoculture is, in light of the reutilization of waste consequences of one creature assortments by another. Shrimp polyculture addresses a noteworthy alternative as opposed to comprehension andor restricting a bit of the issues (for instance environmental pollution, diseases and lessening costs) that shrimp aquaculture has glanced in the past two decades. A couple of creature bunches from grouped trophic levels can be co-refined with shrimps. A conventional data on the species that are opportunities for polyculture and openness of an adequately arranged culture system are the hugest concentrations to consider when co-refined shrimp is cleaned with various species (Martı'nez-Porchas et al, 2010). Change mature enough old ordinary brackish water polyculture is a reasonable choice towards efficient acceleration of aquaculture.

\subsection{Fish Culture with Rice}

Refined fish in rice fields can help control nuisances and weeds, elevate supplement accessibility to rice plants and improve dietary advantages and money related comes back based on what are generally viewed as low info, naturally cordial and increasingly maintainable cultivating frameworks. Incorporating fish culture in flooded and rainfed rice fields additionally utilizes appropriated water assets. Refined fish in rice fields is viewed as a conventional practice in China, Japan and Java; all the more as of late rice-fish culture has been presented by advancement organizations and augmentation administrations to numerous nations in Asia and a developing number in Africa. In any case, incorporated culture of rice and fish requires increasingly refined ranch the board draws near; with ranches planning rice creation and fish culture rehearses and regularly low quality and questionable fish seed creation has compelled broad and long-lasting selection. Rice-fish culture was received broadly in upper east Thailand and West Java, Indonesia and it has been appeared to make a significant commitment to salaries and food security in poor and negligible cultivating networks. An enormous extent of worldwide rice creation isn't under water system, and incorporating of fish culture in rain-fed fields inadmissible to escalated rice trimming can help in growing progressively feasible jobs for 
cultivating networks. Assortment of wild food from rain-fed rice fields has been demonstrated to be significant and is frequently ignored, nonetheless, saw decreases in the accessibility of wild fish and very much created exchanging systems for fish seed from private incubation centers animated the reception of rice-fish culture in upper east. on the off chance that 'harsh water is accessible in close by channels and rivers,P.monodon and winter rice (January-July) are cultivated at the same time in the ghers.' Furthermore, Islam et al. (2005; p. 489) noticed that 'waterfront shrimp (Penaeus monodon) aquaculture in Bangladesh is for the most part drilled in an uncommon kind of field/lake arranged by the side of a waterway - called a Gher - that is utilized to develop rice in winter and shrimp in summer.' These creators noticed that conventional cultivating rehearses, completed in ghers encasing up to 100 ha, typically just comprised of constrained stocking with no taking care of or treatment, and insignificant extent of intercession to oversee water quality
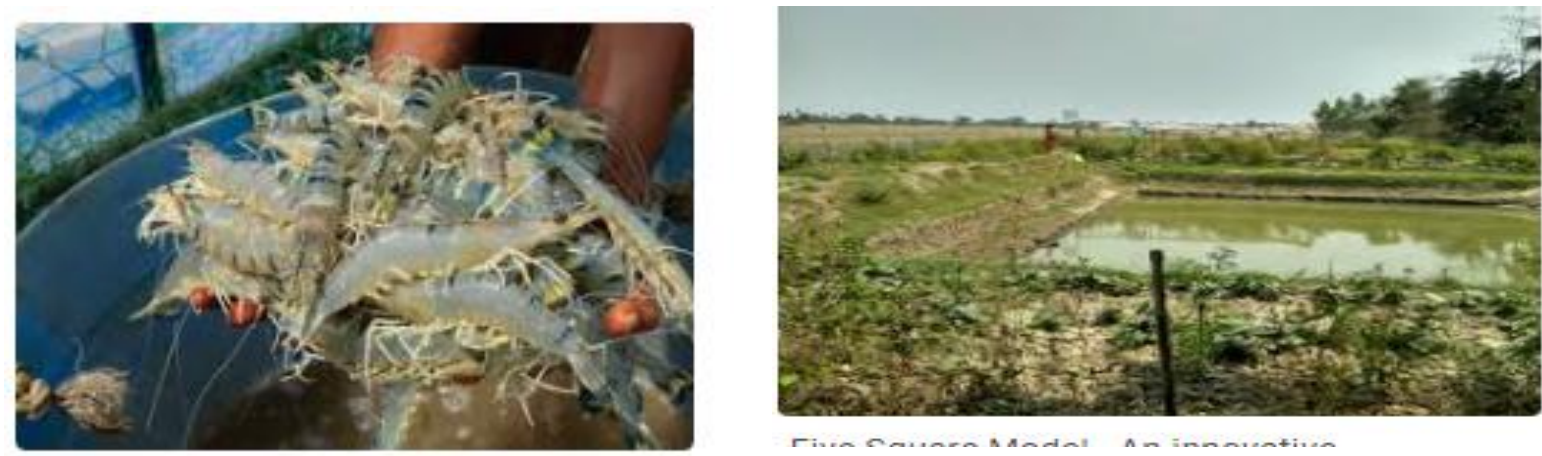

shrimp aquaculture in Bangladesh ...
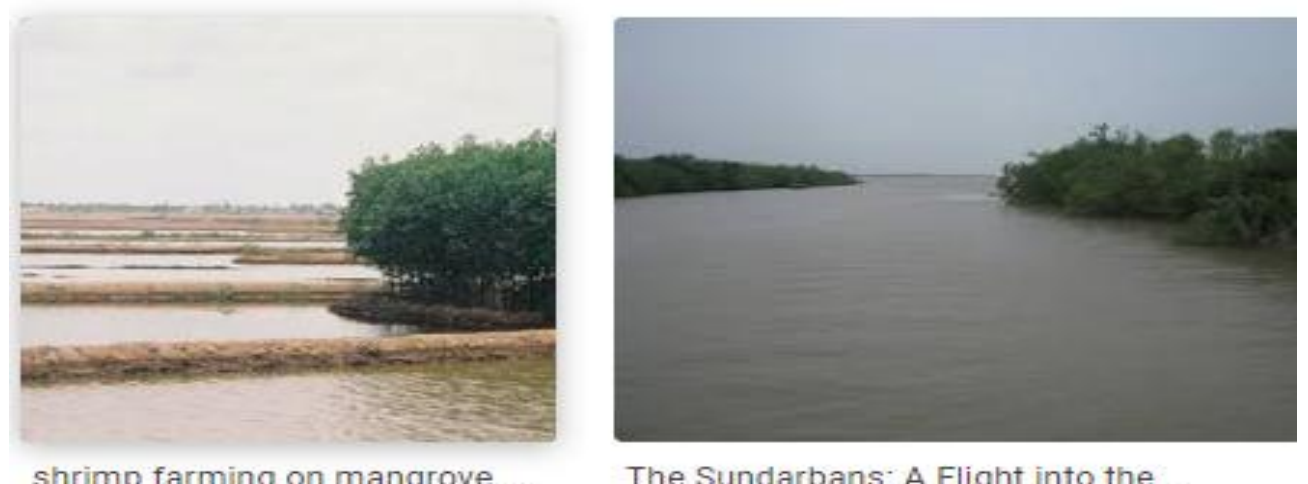

The Sundarbans: A Flight into the.

1:-1. ..............

Fig. shrimps farm

\subsection{Determination of Compatible Species for Polyculture}

Customary brackishwater polyculture through assurance of ideal species for down to earth better creation and advantage were attempted by KRC of ICAR-CIBA including tiger shrimp (Penaeus monodon), Gray mullet (Mugil cephalus), Parsia (Liza parsia), and Milkfish (chanos) to review the perfect species mix. Proximity taking everything into account and nonattendance of one fish creature types in each blend were considered as medications. The examination was finished at ManmathapurMundapara town $\left(21.879493-21.894148^{\circ} \mathrm{N}, 88.263668-88.276199^{\circ} \mathrm{E}\right)$ of Kakdwip hinder in Indian Sundarbans for 240 days during 2013. Lakes were prepared watching standard technique and raised living things were dealt with monetarily open sinking pellet feed (Crude Protein: 24\%, Crude fat: 3\%) @ 2-10\% of fish biomass. Tiger shrimp, dim mullet, parsia and milkfish were stacked @ 2, 0.5, 0.5 and 0.25 no $\mathrm{m}-2$, independently, which were picked reliant on run of the mill practice in traditional developing as revealed from a semi-sorted out gathering based investigation. Best turn of events $(44.17 \pm 1.53 \mathrm{~g})$ of tiger shrimp was practiced in proximity of all species with most insignificant perseverance $(17.9 \pm 3.4 \%)$, and most critical continuance was seen without milkfish $(41.3 \pm 5.6 \%)$ with moderate turn of events $(42.65 \pm 1.25 \mathrm{~g})$. Best advancement of parsia was seen without milkfish $(54.16 \pm 6.34 \mathrm{~g})$, while most raised perseverance was found without diminish mullet $(61.9 \pm 4.1 \%)$. Diminish mullet grew best without milkfish $(487.17 \pm 20.42 \mathrm{~g})$ and persevere through best in proximity taking everything into account $(60.5 \pm 4.4 \%)$. Milkfish grew best without dim mullet $(382.91 \pm 18.39 \mathrm{~g})$, and most imperative perseverance $(71.1 \pm 6.8 \%)$ was found in proximity everything being equivalent. Basically ( $<0.05$ ) higher outright accumulated biomass (1931.64 kg ha-1) was conveyed in proximity 
of all species followed by drugs with nonattendance of parsia (1794.11 kg ha-1), nonappearance of milkfish (1739.42 kg ha-1), and nonattendance of dim mullet (922.51 kg ha-1). Most critical hard and fast pay (INR 520650) was practiced in species mix without milkfish followed by closeness taking everything into account (INR 410303), without parsia (INR 360362), and without diminish mullet (INR 203099 ) with specific bit of leeway cost extent of 2.798, 2.048, 1.824 and 1.242. Advancement, creation and budgetary limits of the assessment demonstrated specific and fiscal possibility of mullets-tiger shrimp polyculture. Mullets-milkfish-tiger shrimp polyculture was in like manner practical anyway with lower benefit.

Change in mean percentage of naturally gravid broodstock between 2007 and 2013

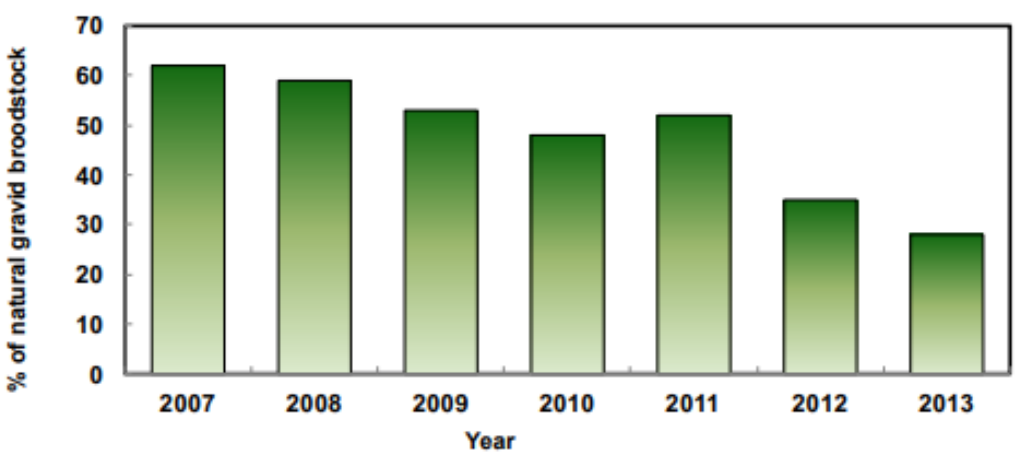

Fig1. Changes in the production

\subsection{Impacts on Mangrove}

The Sundarbans delta extends over the southwest coastal area of Bangladesh, and West Bengal, and contains one of the largest contiguous mangrove forests in the world. As in many parts of the world, mangroves play a vital role in the coastal environment as a cyclone protection belt (in Bangladesh it provides a safety barrier for three greater districts - namely Satkhira, Khulna and Bagerhat), as a habitat for juvenile fish and crustacean species and through the supply of a variety of products (e.g. shellfish and wood) to the local population. Considerable areas of mangroves have been reduced in Bangladesh since the beginning of the initial expansion of shrimp farming in the early 1980s (Figure 9). Causes for the degradation of mangroves include land conversion for aquaculture and other uses, timber and fuel wood collection, and grazing, along with natural causes such as cyclone damage. Mangroves are salt tolerant forest ecosystem of tropical and subtropical intertidal regions of the world and are important resources in coastal ecosystems that contribute multiple ecosystem services. Mangrove forests offer both tangible and intangible benefit to coastal peoples. With coastal geo-morphological changes, mangroves are facing rapid change brought about by social requirements, where population pressure for food production and urban development has changed mangrove habitat into ecologically undesirable states along coastlines globally. The Bangladesh coast supports approximately 503000 ha of natural mangrove forest and plantation, which represents approximately 3.9 percent of the total land mass and 15 percent of the total land canopy cover of the country the great majority of which lies in the Sundarbans Reserve Forest (SRF) in the southwest region. Due to population pressure, the mangrove forest has been gradually shrinking due to conversion of forestland to human settlement, agricultural land and to aquaculture development . implications of increased coastal erosion, loss of livelihood for coastal communities, reduction of natural fish and shellfish production and environmental degradation, shrimp farming and salt production is not more profitable at a national level given the losses incurred. Damage is caused by pollution and by clearing of the vegetation to make way for new farms. Chemical pollutants used in the process include antibiotics, fertilizers, disinfectants and pesticides, which could be harmful for human health as well as for the environment. There is no specific advantage for people to build shrimp farms in mangrove areas compared to other areas; but it is done because it is common land that people can get hold of cheaply. The Chakaria Sundarban is located in Chakaria upazilla of Cox's Bazar District in Bangladesh. The area is the extended plain landmass located between $21^{\circ} 35^{\prime} \mathrm{N}$ to $21^{\circ} 48^{\prime} \mathrm{N}$ latitude and $91^{\circ} 57^{\prime} \mathrm{E}$ to $92^{\circ} 05^{\prime} \mathrm{E}$ longitude. Chakaria is bordered by the Matamuhuri-Harbang khals is the north, the confluence made khal at the south, the Cox's Bazar-Chittagong highway in the east and the Maheskhali Channels in the west. The Chakaria Sundarban area at the mouth of the Matamuhuri river has been almost completely destroyed by shrimp culture, and salt farming, leaving only some patches and bushes, totaling approximately 411 acres. 


\subsection{Waterlogging and Saline Interruption}

The coast is an amazingly weak piece of one of the most flood prone nations on the planet. Waterlogging and saline interruption are distinguished as serious issues in the vast majority of the shrimp cultivating regions of Bangladesh. Before 1960 individuals utilized flowing water for hydroponics, where waterlogging for significant stretches and salt interruption in soils was not an issue. With the structure of polders during the 1960s, furthermore, especially through the 1970s, in addition to solid worldwide market request and significant expenses urged ranchers to improve shrimp cultivating in polders. All the more as of late rice development is not, at this point monetarily reasonable because of salt water interruption, and the mix of components (i.e., solid market request and significant expense of shrimp) went about as an impetus to quicken shrimp cultivating improvement in this way improving the probability of further waterlogging rate. Networks in southwest Bangladesh experience delayed flooding that does not retreat effectively, and brings about pools of stale water in their fields. Appraisals of the quantity of individuals influenced by waterlogging after some time shifts, however government information from 2011 demonstrates that in excess of 800000 individuals were influenced that year in Satkhira Area alone after overwhelming storm downpours. An October 2013 report by Shushilan, a NGO revealed that in excess of 21000 families in Sathkira District are consistently influenced by waterlogging. While an assortment of variables leads to waterlogging, it is most articulated in zones where the land is isolated by raised earthen banks or then again polders (IRIN, 2013), which lessen the open door for waters to retreat. Examination shows that the development of dikes frequently brings about expanded stream sedimentation, where residue and flotsam and jetsam develop in riverbeds as opposed to being kept on level land during floods (UNESCO, 2011). This outcome in the riverbed levels rising and water profundity falling. At the point when dikes are set up and water spills over the edge during an elevated tide or overwhelming precipitation, caught water can't retreat, driving to waterlogging (Figure 12), which has influenced a few regions for over 10 years. Numerous individuals have needed to move their estates various occasions and individuals have needed to leave their family land or cultivating plots in light of the fact that those were gone to lakes. While some relocate, others have changed in accordance with the extended waterlogging by developing fish, prawns, or shrimp. In any case, utilizing waterlogged land for business development of shrimp prompts expanded water saltiness, which makes soil become fruitless for some other types of development (for example rice, crops and so on.). Many contend that shrimp cultivates likewise cover the more extensive issue of waterlogging, rather than catalyzing networks to request long haul answers for the issues that waterlogging and salt interruption cause (Rahman et al., 2013). Indeed, even in the best case, shrimp cultivating can keep going for a flat out limit

\subsection{Effect of Shrimp Cultivating}

The time ranchers figure out how to develop shrimp, the earth is so gravely harmed they can't turn around to edit or other cultivating when shrimp cultivating fall flat. 3.5.2 Salinization of land and water Drawn out shrimp cultivating builds the dirt saltiness, corrosiveness, and drains soil calcium, potassium, magnesium and natural carbon content which prompts soil corruption (Ali, 2006). Before the shrimp cultivating began, rice was developed on 80 percent of the cultivable land and gathered two times every year, in February-March and July-August. Rice yield was enhanced by growing various heartbeats, vegetables and natural products. The expanded saltiness because of shrimp development realized declined rice and different harvests creation (Swapan and Gavin, 2011), in light of the fact that shrimp cultivating causes salinization in the nearby rice and other rural grounds. Land immersion by saline water for extensive stretches prompts its permeation into the encompassing soils, coming about in adjusted soil science (Islam, 2003). An examination directed by Ali (2006) in the town of Damarpota in Satkhira locale of Bangladesh demonstrated that extended shrimp cultivating in the territory came about to lost 1049 tons of rice creation during the time of 1985 to 2003. Besides, saltiness interruption influences freshwater supplies for water system and individuals expected to introduce profound cylinder well to pick up the required freshwater, which straightforwardly influenced groundwater springs.

\section{EFFECTS OF SHRIMP FARMING ON FARMERS}

\subsection{Medical Problems}

Because of delayed time spent on ocean water it might causes bunches of wellbeing related issues in both male and female, it has been accounted for that few kinds of illnesses like skin issues ,waterborne ailments conceptive lot ailments particularly in females, and additionally causes contigious diseases.a 
concentrate on the wellbeing impacts of shrimps ranchers has uncovered this reportamong the respondent of sagar island $86 \%$ of the homestead are affected by the mid yield stage and $8 \%$ of homestead were influenced by mid and end crop phase.Among the inhabitants of Basanti square $73 \%$ of homestead are influenced in the mid harvest stage and 15\% of ranchers of homestead are experienced with ailments in their mid-phase, about $4 \%$ of ranch ranchers are affected with this diseases.overall uncovering the information watched together it is seen that most extreme degree of sickness contamination is found during the mid-stage.

\subsection{Kinds of Physical Harm of Shrimps Authorities}

The impacts and harm happened during shrimps assortment of the rancher are seen by doing an overview on a no of rancher associated with this work and a gathering of rancher which isn't engaged with this job.two gathering of female ranchers are taken for this review ,from sajenkhali and sandeshkhali sunderban, one gathering of females are associated with the family residential work and other gathering were engaged with the prawn assortment for delayed time in ocean water.the females family unit work is given a great deal of physical work and exercises that is the reason they are experiencing lower back torment knees agony and uneasiness in body.the female prawn gatherers ranchers are compelled to do an extremely difficult activity manual and truly requesting work for assortment of prawns they gather seeds for procuring of their family.during this procedure they endured a ton and they need to invest a ton of energy in ocean water.during this work they accomplish a few physical work like hauling of nets forward and in reverse and afterward spreading of nets and afterward assortment of seeds the female rancher experiences an enormous physical inconvenience ,stress and proned to many sort of maladies like waterborne skin issues and conceptive diseases.so it is seen in both the gatherings that the female ranchers associated with prawn assortment are enduring a ton of physical distress ,mental pressure, serious torment in body .they likewise experienced ailments .therefore pawn authorities are is by all accounts proned to numerous physical issues and stress which influence their wellbeing and conduct.

\subsection{Social Problems}

As the meendharas the prawn gatherers, ceaselessly gather prawn seeds, all through year the prawn seeds are first gathered from authorities and are then planted in a paddy field or in the bheries (the region encased with the bitter water a shallow lying zone around 6-8 $\mathrm{ft}$ deep.)these are immersed with harsh water and in the wake of collecting of the fields the aquaculture exercises are conveyed on.after the time of a half year completely developed prawns are taken out the field are again developed with paddy in the stormy season. the adolescent of tiger prawns becomes grown-ups in 4-6 months.the best period of planting the seeds of the tiger prawn is winter season, particularly in the long stretches of December January.it may keep on february,and request of the tiger prawns are most extreme in December and least in the long stretches of September months. the cost of prawns at kamdebnagar town is as given per season as information assortment:

- Summer season: Rs 200/1000

- Stormy season: Rs 250/1000

- Harvest time season: Rs 16-40/1000

- Winter season: Rs 400/1000

According to the information above we can see that the aquaculturists gathers seeds from the meendharas (seed authorities) in the town, the rates changes in a huge proportion according to information request of prawn are more in winter season.at summer and harvest time season it is extremely low, it takes very nearly 4-5 days to gather 1000 prawn then they sell fifth day.it is seen that the yearly pay by selling prawns isn't sufficient for satisfying each need of the family, it isn't exactly acceptable for the family. Financially the expectation for everyday comforts of the meen dharas are poor and is carrying on with hard life. the womans and childrens are both associated with this work and socially and financially they are very backward.the youngsters are not getting instruction and the security of lady is likewise not there. the rehearsing of shrimp culture propagates the division of work and social hierarchy, and additionally relates with numerous angles like destitution, illeteracy, kid work ,exploitation.the men include chance their lives in procuring yet it doesn't appears to work it campels to work to womens and childrens too,they still unpaid and immensely neediness influenced. The 
Juvenile Tiger prawn takes its full size inside 4 to a half year. Best season for planting tiger prawn seeds is winter center of December to January. ladies and childrens partake in fry assortment and fry selling either as a family catcher or autonomously., social, conservative and strict elements can appraise the degree of womens contribution and acknowledgment of work. ladies of the least fortunate family by and large engaged with this work, the business is partitioned in two stages in one the men and male youngsters got fry and took back to shore or to home, where the womens and female childrens sorts the fry .

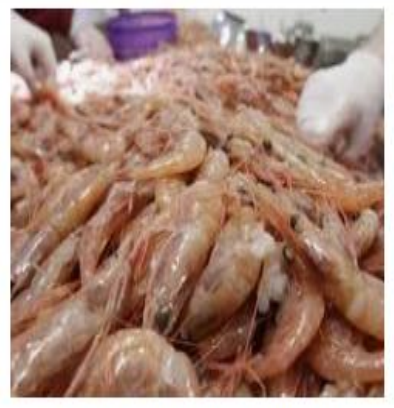

Feed Supplement Shrimp Culture, Aqua indiamart.com

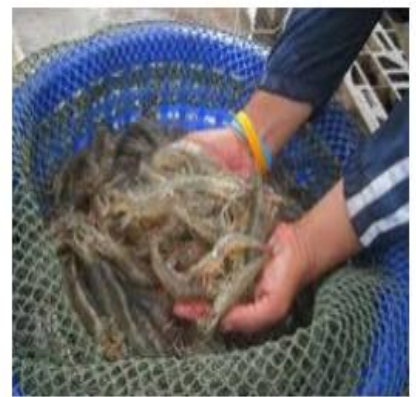

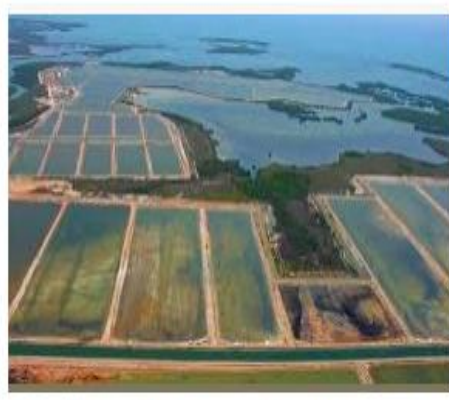

Environmental Problems of Aquaculture earthjournalism.net

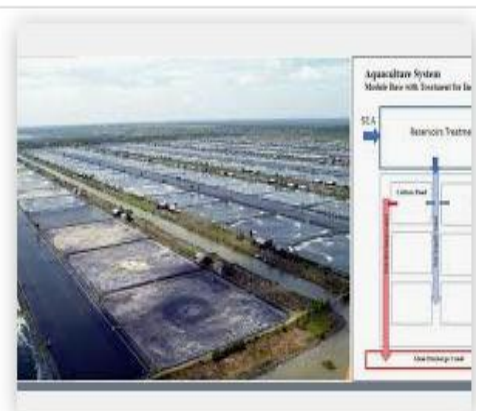

intensive shrimp farming systems... aquaculturealliance.org
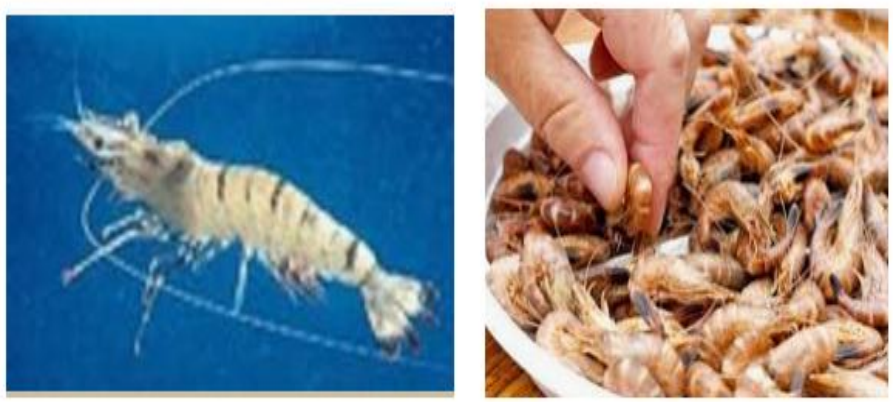

\subsection{Occupational Hazards}

The shrimp's farmers are often become victims of attack from crocodiles and sharks. this is a very serious problem and also a great threat for their life. if they become victim their family condition become very worse. Constant touch with saline water also creates health hazard. Several cases of skin problem are noted due to continuous immersion in brackish water. There are several hindrances for the catching of prawn seeds. They are, attack from tigers on the land and crocodiles in the water. Health hazards in the form of skin disease etc. are present. There are a few obstacles for the getting of prawn seeds. They are, assault from tigers on the land and crocodiles in the water. Wellbeing dangers as skin malady and so forth are available. Bagdis of Sunderbans who came as worker to clear the backwoods and settled in the land under Jamindars turned into the Meendharas in course of time. a large portion of the Meendharas can't bear the cost of a pontoon to gather the prawns,as they are poor yet as this calling make them cash they are limited to do as such subsequent to confronting such huge numbers of perils.

Another option, fake reproducing grounds are readied. Lasting incubators are made. Mother prawns are raised there and falsely brings forth and seeds are reared. The specialists (MPEDA) have made overview with respect to the risks to the Meendharas. Misleadingly brings forth and seeds are reared. Such reproducing grounds are available; the reproducers may raise two yields of grown-up tiger prawns thusly.

\section{CONCLUSION}

Refined fish in rice fields can help control vermin and weeds, elevate supplement accessibility to rice plants and improve healthful advantages and monetary comes back based on what are generally viewed as low info, ecologically well-disposed and progressively reasonable cultivating frameworks. Incorporating fish culture in inundated and rainfed rice fields additionally utilizes appropriated water assets. Refined fish in rice fields is viewed as a customary practice in China, Japan all the more as of late rice-fish culture has been presented by improvement organizations. what's more, the incorporated culture of rice and fish requires increasingly refined homestead the board draws near; with ranches planning rice creation and fish culture rehearses and regularly low quality and inconsistent fish seed creation has obliged far reaching and long-lasting appropriation. Rice-fish culture was embraced 
generally in and it has been appeared to make a significant commitment to livelihoods and food security in poor and minimal cultivating networks

There are a few blocks for the getting of prawn seeds. They are, assault from tigers on the land and crocodiles in the water, Health risks as skin sickness and so forth are available. the modifications in the occupations structure and flourishing of rural nuclear families following the introduction of shrimp aquaculture. More significant compensation nuclear families normally had more compensation from shrimp developing and related pay openings than the lower and focus pay families. Business shrimp aquaculture had clearly added to an extending opening among the families. The results of this examination demonstrated that quick changes in neighborhood land-use systems, ownership, additionally, the board practices of shrimp develop considering shrimp aquaculture had weakened the compensation picking up odds of the lower pay families and it showed up similarly to have provoked extended monetary detachment through growing landlessness and in this manner extended pay irregularity and lack of protection. The outcomes presented in this part shown shrimp aquaculture appeared to have been a huge business improvement for more significant pay nuclear families, particularly for the land-having nuclear families. The dissemination of the pay it made was uneven for the social affairs who controlled the land and resources imperative to check out the development. There were confined decisions for lower pay families to take an intrigue and bit of leeway due to their limited land ownership. The huge decline of agricultural landscapes affected by unconstrained shrimp developing had caused the demolition of trees and estates, and lessened green harvests and creature's creation in the assessment area. The results showed that the alterations in land use, loss of mangrove resources, reducing number of tamed animals and utilization of yield based cultivating and work openings were applying extraordinary load on neighborhood livelihoods and the practicality of the Sundarbans region by and large. Neighborhood appearances of frailty were associated with factors including: land residency structures that compelled access to land; nonappearance of employment open entryways for getting a compensation in the zone due to the loss of cultivation and tamed creatures and methods of characteristic corruption (raising pungency, infertility); and increasing expenses of basic items (as basic staples, for instance, rice and vegetables were being imported)

\section{REFERENCES}

[1] Ahmed, N., Troell, M., Allison, E.H., Muir, J.F., 2010b. Prawn postlarvae fishing in coastal Bangladesh: Challenges for sustainable livelihoods. Marine Policy 34, 218-227

[2] Azad, A.K., Jensen, K.R., Lin, C.K., 2009. Coastal aquaculture development in Bangladesh: unsustainable and sustainable experiences. Environmental Management 44, 800-809.

[3] Baird, D.J., 1994. Pest control in tropical aquaculture: an ecological hazard assessment of natural and synthetic control agents. Mitt. Internat. Verein. Limnol. 24, 285-292.

[4] Beveridge, M.C.M., Phillips, M.J., 1993. Environmental impact of tropical inland aquaculture. In: Pullin, R.S.V., Rosenthal, H., Maclean, J.L. (Eds.), Environment and Aquaculture in Developing Countries. ICLARM, Conf., Proc., 31., pp. 213-236.

[5] Bosma, R.H., Jumnongsong, S., Dulyapurk, V., Sidik, A.S., Dao, P.T.A., Tuan, L.X., van Zwieten, P.A.M., Bunting, S.W., 2010. Mangrove ecosystems and the sustainability of related livelihoods. Poster presentation, Global Aquaculture Conference 2010, 19 Sept 2010, Phuket, Thailand.

[6] Bunting, S.W., 2010. Knowledge and attitudes concerning sustainable aquaculture, fishing and livelihoods in the Indian Sundarbans. Darwin Initiative Scoping Award Report. interdisciplinary Centre for Environment and Society, University of Essex, UK.

[7] Bunting, S.W., (forthcoming) Principals of sustainable aquaculture: promoting ecological, economic and social resilience. Earthscan. Bunting, S.W., Pretty, J., Edwards, P., 2010. Wastewater-fed aquaculture in the East Kolkata Wetlands

Citation: Anupma kumari, “Shrimp Culture”, International Journal of Innovative Studies in Aquatic Biology and Fisheries, 6(3), pp. 34-42. DOI: https:// doi.org/10.20431/2454-7670.0603005

Copyright: (c) 2020 Authors, this is an open-access article distributed under the terms of the Creative Commons Attribution License, which permits unrestricted use, distribution, and reproduction in any medium, provided the original author and source are credited. 